\title{
АЛЬФА-АКТИВНОСТЬ ЭЭГ И СОСТОЯНИЕ ЭЛЕМЕНТНОГО БАЛАНСА В ОРГАНИЗМЕ ПОДРОСТКОВ
}

\author{
Е.В. Евстафьева, О.А. Залата, С.А. Зинченко, \\ И.А. Евстафьева, А.Г. Трибрат
}

КФУ имени В.И. Вернадского, Медицинская академия им. С.И. Георгиевского; 295006, бульвар Ленина 5/7, г. Симферополь, Россия

РЕЗЮМЕ. В условиях химического загрязнения среды изменяется баланс между химическими элементами (ХЭ), играющими важную роль в протекании нервных процессов. С целью определения значимости 28 ХЭ в обусловливании базового ритма электроэнцефалограммы (ЭЭГ) обследованы 119 городских подростков 12-14 лет. Химические элементы определяли в пробах волос рентгено-флуоресцентной спекторофотометрией; ЭЭГ регистрировали при трех функциональных пробах в 10 отведениях. По результатам корреляционного анализа определяли нейротропность ХЭ с учетом силы и значимости корреляционных связей содержания ХЭ со спектральной мощностью альфа-ритма. Нейротропность ХЭ была более выражена для токсичных тяжелых металлов при их содержании в пределах условной нормы, в то время как дефицитное содержание эссенциальных ХЭ было значимо главным образом при пробе «открывание глаз».

КЛЮЧЕВЫЕ СЛОВА: химические элементы, волосы, подростки, альфа-ритм, ЭЭГ.

\section{ALPHA EEG ACTIVITY AND ELEMENTAL BALANCE IN ADOLESCENT ORGANISM}

\section{E.V. Evstafeva, O.A., Zalata, S.A. Zinchenko, I.A. Evstafeva, A.G. Tribrat}

KFU named after V.I. Vernadsky, Medical Academy named after S.I. Georgievsky, 295006, Lenin Boulevard 5/7, Simferopol, Russia

ABSTRACT. Under conditions of chemical pollution of the environment, the balance between chemical elements (CE), which play an important role in the course of neural processes, is changed. To determine the significance of $28 \mathrm{CE}$ for the basic rhythm of the electroencephalogram (EEG), 119 urban adolescents 12-14 years old were examined. CE was determined in hair samples by X-ray fluorescent spectorophotometry. EEG in 10 leads was recorded with three functional states. Based on the results of correlation analysis, neurotropic effect of CE was determined taking into account the strength and significance of correlations between CE content and the spectral power of alpha rhythm. The "neurotropic" effect of $\mathrm{CE}$ was more expressed for toxic heavy metals at their content within the conditional norm, while the deficient content of essential CE was significant mainly in the eye-opening test.

KEYWORDS: chemical elements, hair, teenagers, alpha rhythm, EEG.

\section{ВВЕДЕНИЕ}

Элементный гомеостаз мозга важен для нормального протекания нервных процессов, однако в условиях химического загрязнения окружающей среды баланс между эссенциальными и токсичными элементами существенно изменяется. Одним из «уязвимых» периодов является пубертатный, когда происходит становление механизмов нейроэндокринной регуляции.

Цель настоящго исследования - определение нейротропности ряда токсичных, условно токсичных, эссенциальных и условно эссенциальных элементов в обусловливании базовых ритмов электроэнцефалограммы (ЭЭГ) у подростков.

\section{МАТЕРИАЛЫ И МЕТОДЫ}

С соблюдением правил биоэтики было обследовано 119 школьников разного пола в возрасте 12-14 лет. Все испытуемые были без существенных отклонений в состоянии здоровья, проживали в г. Симферополе. Методом рентгенофлуоресцентной спектрофотометрии в пробах волос определяли 28 химических элементов (ХЭ). Функциональное состояние центральной нервной системы оценивали посредством регистрации текущей ЭЭГ-активности во фронтальных, центральных, теменных, височных и затылочных локусах согласно международной системе «10-20», в состоянии спокойного бодрствования (глаза закрыты, глаза открыты) и при решении арифметической задачи (обратный счет в 
уме) с закрытыми глазами. Нейротропность ХЭ в баллах определяли по результатам непараметрического корреляционного анализа по Спирмену, учитывая силу и значимость корреляционных связей (Евстафьева и др., 2016) ХЭ со спектральной мощностью альфа-ритма.

\section{РЕЗУЛЬТАТЫ И ОБСУЖДЕНИЕ}

У обследованных подростков установлен дефицит эссенциальных элементов $\mathrm{Zn}, \mathrm{K}, \mathrm{Fe}, \mathrm{Cu}, \mathrm{Se}, \mathrm{Mn}, \mathrm{S}, \mathrm{Br}$ и $\mathrm{Cl}$. Превышений токсичных элементов не наблюдали, а I, Ag, V, Mo, Ti, Ba, Sb, Sn и Bi в пробах волос не обнаружены. Корреляционный анализ позволил выявить высокозначимые корреляционные связи $(0,000<p<0,01)$ при их слабой и средней силе $\left(0,21<\mathrm{R}_{\mathrm{s}}<0,60\right)$. При этом наибольшее число корреляционных связей и более высокие значения коэффициентов корреляций наблюдались при пробе на открывание глаз (99), при закрытых глазах выявлено 73 значимых корреляции, а наименьшее их число (43) - при арифметическом счете.

Ряды нейротропности ХЭ по результатам корреляционного анализа распределились при разных пробах следующим образом:

глаза закрыты:

As (54) $>\mathrm{Se}(33)>\mathrm{Cr}(29)>\mathrm{Sr}(28)>\mathrm{Cd}, \mathrm{Ni}(26)>\mathrm{Pb}(25)>\mathrm{Co}(15)>\mathrm{Hg}(13)>\mathrm{Ca}, \mathrm{Zn}$,

$\mathrm{Cu}(8),>\mathrm{Fe}(4)>\mathrm{Rb}(3)$;

глаза открыты:

$\mathrm{Pb}(52)>\mathrm{As} \mathrm{(50)}>\mathrm{Ni}(47)>\mathrm{Zn}(46)>\mathrm{Ca} \mathrm{(39)}>\mathrm{Cu}(38)>\mathrm{Sr}(32)>\mathrm{Se}(23)>\mathrm{Fe}(21)>\mathrm{Cr}(19) \mathrm{Rb}(13)$

$>\mathrm{Br}(9)>\mathrm{Cl}(6)$;

арифметический счет:

$\mathrm{Hg}(50)>\mathrm{Zn}(35)>\mathrm{As}(24)>\mathrm{Cl}(23)>\mathrm{Pb}(21), \mathrm{Ni}(4)>\mathrm{Mn}, \mathrm{K}, \mathrm{Co}(3)$.

При разных пробах значимость ХЭ несколько различалась, но в целом роль эссенциальных элементов в обусловливании мощности такого базового ритма ЭЭГ как альфа-ритм проявляла себя в наибольшей степени при десинхронизации ЭЭГ при открывании глаз, а в наименьшей - при арифметическом счете. В то же время условно токсичные (эссенциальные) и особенно токсичные тяжелые металлы при их содержании, не превышающем референтные значения, обнаруживали бо́льшую нейротропную активность при всех пробах. По результатам всех трех проб значимость ХЭ для спектральной мощности альфа-ритма распределилась следующим образом:

$\mathrm{As}(128)>\mathrm{Pb}(98)>\mathrm{Zn}(89)>\mathrm{Ni}(77)>\mathrm{Hg}(63)>\mathrm{Sr}(60)>\mathrm{Cr}(48)>\mathrm{Ca}(47)>\mathrm{Cd}(26)>\mathrm{Fe}(25)>\mathrm{Co}(18)>\mathrm{Rb}(16)$.

\section{ВЫВОДЫ}

Нейротропность ХЭ по отношению к спектральной мощности альфа-ритма была более выражена для токсичных тяжелых металлов при их содержании в пределах условной нормы, в то время как дефицитное содержание эссенциальных ХЭ проявляло свою значимость главным образом при пробе «открывание глаз». Характер установленных связей требует отдельного анализа.

\section{Анализ ртути выполнен при финансовой поддержке Российского фонда фундаментальных исследований (проект № 18-29-24212).}

\section{Список литературы / References}

1. Евстафьева E.B., Залата О.А., Евстафьева И.А. Способ оценки влияния биоэлементов на функциональное состояние центральной нервной системы. Патент на полезную модель №164769 Гос. Реестр полезных моделей РФ 26.08. 2016 г. (Evstaf'eva E.V., Zalata O.A., Evstaf'eva I.A. Sposob ocenki vliyaniya bioelementov na funkcional'noe sostoyanie central'noj nervnoj sistemy. Patent na poleznuyu model' №164769 Gos. Reestr poleznyh modelej RF 26.08. 2016 (in Russ)). 